\title{
Morbimortalidade infantil por diarréia aguda em área metropolitana da região Nordeste do Brasil, 1986-1989*
}

\author{
Infant morbimortality due to acute diarrhoea in a metropolitan area of \\ northeastern Brazil
}

\author{
Gilvana de J. do V. Campos, Stelito A. dos Reis Filho, Antônio Augusto M. da Silva, \\ Maria Ayrecilla da S. Novochadlo, Raimundo A. da Silva, Clóvis E.S. Galvão \\ Universidade Federal do Maranhão - Curso de Medicina (G.J.V.C. e C.E.S.G. - bolsistas CNPq) \\ Departamento de Saúde Pública da Universidade Federal do Maranhão - Brasil (A.A.M. S.; M.A.S.N.; R.A.S.) \\ Departamento de Patologia da Universidade Federal do Maranhäo (S.A.R.F)
}

\begin{abstract}
Foi realizado inquérito domiciliar do tipo transversal abrangendo crianças menores de cinco anos residentes em 3 áreas da ilha de São Luis (Brasii): Vila Paimeira, Anjo da Guarda e São José de Ribamar. Aplicou-se um questionário onde se perguntou à măe ou à pessoa responsável pela criança sobre a presença de diarréia nas duas últimas semanas. Foram realizados dois estudos censitários (maio de 1986 e 1989) e quatro amostragens sazonais (novembro de 1986 , 1987 e 1988 e maio de 1989). A prevalência de diarréia foi maior em maio de 1986 e novembro de 1987; São José de Ribamar foi o local de maior prevalência; a distribuição dos casos por idade mostrou maior prevalência entre crianças de 6 a 11 meses $\theta$ de 1 a 2 anos de idade; a prevalência da diarréia foi maior nas familias que tinham como destino dos dejetos a maré e fossa negra: que se abasteciam de água de poço descoberto, nas famílias cujos pais eram desempregados e nas que depositavañ o lixo na maré. A diarréia foi a principal causa de morte nos dois estudos censitários; a taxa de mortalidade infantil em maio de 1986 fol, respectivamente, de 44,0 por mil em menores de um ano 12,8 por mil em menores de cinco anos; em maio de 1989 foi de 7,9 por mil e 4,9 por mil. As reduções na morbidade e mortalidade infantil por diarréia aguda entre 1986 e 1989 foram estatisticamente significantes.
\end{abstract}

Diarréia, epidemiologia. Mortalidade infantil.

\section{Introdução}

A diarréia constitui uma das principais causas de morbimortalidade em crianças menores de cinco anos de idade, principalmente em menores de um ano, e, por isso, é considerada um grave problema de saúde pública $6.21,26$.

Nos países de Terceiro Mundo, foi estimado, no ano de 1980, pela Organização Mundial da Saúde (OMS) e Unicef, que 800 milhões adoecem e 4,6 milhōes de crianças menores de cinco anos morrem anualmente, tendo como causa as enfermidades diarréicas. Sessenta a $70 \%$ desses óbitos ocorrem devido às más condições nutricionais das cianças 9.11,21. Em 1993, estimou-se que 3,3 milhōes de crianças menores de cinco anos continuaram morrendo por ano devido à doença diarréica. Apesar da grande reduçāo na mortalidade global pela doença diarréica no mundo, o número da crianças que falecem continua bastante aito. Foi de 2,6 o número de episódios diarréicos por criança/ano estimados no mundo em 1993. Na faixa etária de 6 a 11 meses, o número de episódios/criança/ano chegou a 5 , e em localidades pobres da América Latina, este número foi estimado em 10 ou mais episódios/criança/ano 5 .

\footnotetext{
* Trabalho realizado como parte do PRODIMMA (Projeto de Controle da Doença Diarréica Infantil no Maranhäol e com auxilio financeiro da GTZ (Sociedade Alemā de Cooperą̧äo Técnica).

Separaratas/Reprints: - Antônio Augusto Moura da Silva - Departamento de Saúde Pública - Universidade Federal do Maranhao. UFMA - Largo dos Amores, 21 - Centro - 65020-240 - Säo Luís. MA - Brasit

Fone: $\{098\} 232.5495$ Fax: $\{098,232.3911$

Recebido em 14.6.1994. Aprovado em 22.2.1995.
} 
A OMS, desde o ano de 1978, estabeleceu, em nível mundial, o Programa de Controle de Doenças Diarréicas, visando basicamente à redução da morbimortalidade por diarréia aguda ${ }^{4,22}$.

O Brasil e um dos países mais atingidos pelo problema da diarréia, repercutindo diretamente sobre as taxas de mortalidade infantil1.4, sendo que, anualmente, morrem 50 mil crianças menores de um ano em conseqüência da diarréia; essa alta mortalidade está associada a vários fatores, entre eles o de que a maior parte da população vive em condições precárias e subumanas. As condiçőes socioeconômicas da população funcionam como fator de grande importância nesse processo ${ }^{16}$.

Fatores como o desmame precoce, a contaminaçāo dos alimentos e da água potável e a desnutriçāo são predisponentes ao aparecimento da diarréia aguda 24 .

Há indicadores de que a mortalidade infantil proporcional por diarreia esteja se reduzindo. Em Pelotas, no ano de 1982, a diarréia constituiu a quinta causa de óbito em menores de um ano, representando $12 \%$ dos óbitos nesta idade ${ }^{2}$. Grande parte desta redução da mortalidade proporcional por diarréia está sendo creditada à Terapia de Reidratação Oral (TRO) ${ }^{1}$, mas é difícil medir-se o impacto dos diversos componentes de um programa de controle da doença diarréica na redução dos níveis de mortalidade infantil por diaréia ${ }^{5}$.

Para que se tenha uma idéia da importância dos indicadores sanitários sobre a doença diartéica, é necessário que se saiba que se a mesma fosse controlada do ponto de vista epidemiológico, a mortalidade infantil teria sua taxa diminuída de um terço ${ }^{13}$.

No Maranhão, como nos Estados do Nordeste brasileiro, a diarréia ocupa papel de importância. Entre 1981 e 1988, a taxa de mortalidade infantil apresentou uma redução a cada ano, quando passou de 104 em 1980 para 60 por mil em 1988. Em $87-88$, a diarréia foi responsável por $30 \%$ da mortalidade infantil no Maranhão, superior à média nacional e regional. Vários fatores têm impedido que a taxa de mortalidade infantil decresça no Maranhāo, e um dos mais importantes é a doença diarréica ${ }^{7}$.

Observa-se precariedade de informação sobre dados de morbimortalidade por diarréia nos centros urbanos brasileiros e, especialmente no Nordeste. Faltam trabalhos sobre a utilização da TRO e seu impacto na redução da mortalidade infantil nas cidades brasileiras. $O$ melhor conhecimento desses aspectos facilitara a toma- da de medidas de controle da diarréia e melhor acompanhamento e avaliação dos programas de controle da morbimortalidade por essa doença no Brasil.

Devido à importância que a diarréia infantil continua tendo na mortalidade infantil, foi realizado o presente trabalho, que teve como objetivos estudar a prevalência da diarréia infantil em crianças menores de cinco anos de idade, analisar a mortalidade infantil geral e mortalidade infantil por diarréia aguda, investigar o diferencial da morbidade nas áreas estudadas e verificar a ocorrência de diarréia segundo a idade da criança e outros fatores socioeconômicos e ambientais. Os dados, coletados em Sāo Luís, Maranhão, podem fornecer pistas do comportamento dos padrōes de morbimortalidade da diarréia em crianças de outros centros urbanos brasileiros, com características semelhantes.

\section{Material e Método}

Foi realizado inquérito domiciliar do tipo transversal abrangendo todas as crianças menores de cinco anos residentes nos bairros de Vila Palmeira e Anjo da Guarda, localizados no Município de Sāo Luís, e São Raimundo e José Câmara, no Município de São José de Ribamar, Estado do Maranhão (Ilha de São Luís).

Os locais foram escolhidos de maneira a atingir áreas de ocupação antiga, dotadas de melhor infra-estrutura sanitária e serviços de saúde regulares (vila Palmeira), áreas de ocupação mais recente (Anjo da Guarda) e áreas localizadas em outro município (São José de Ribamar). Para fins de análise, São José de Ribamar foi considerada como uma única localidade.

Forarn realizados dois estudos censitários; o primeiro em maio e junho de 1986, e o segundo, em maio de 1989. Quatro amostragens sazonais foram feitas para se comparar a variação sazonal na prevalência das doenças diarréicas entre a estaçāo chuvosa (maio) e a não chuvosa (novembro). Utilizou-se amostragem aleatória simples, incluindo em torno de $12 \%$ dos domicílios cadastrados no estudo censitário de 1986.

Aplicou-se questionário padronizado que continha indicadores socioeconômicos referentes às famf́lias entrevistadas (renda familiar, escolaridade, relação dos pais no emprego e faixa etária das crianças); dados com relação às condições de moradia (destino do lixo e dejetos, tipo de abastecimento de água utilizado pelas famílias) e 
informaçōes referentes à diarréia (número de episódios diarréicos nas duas últimas semanas e causa da morte).

Perguntou-se à mâe ou à pessoa responsável pela criança sobre a presença ou não de episódios de diarréia nas duas últimas semanas.

Considerou-se como diarréia aguda a presença de 4 ou mais evacuaçōes líquidas com evolução de até 7 dias. Indagou-se, ainda, sobre a ocorrência de óbitos infantins e sobre a causa básica de cada morte detectada nos doze meses anteriores à entrevista.

As entrevistas foram realizadas por estudantes de nível médio e superior que passaram por seleçăo e treinamento e foram supervisionados pelos coordenadores do projeto.

Para análise da morbidade e mortalidade, utilizaram-se os seguintes indicadores: para morbidade, a prevalência de diarréia infantil em crianças menores de cinco anos nas duas últimas semanas, em maio-86 e maio-89; e para a mortalidade, o número de óbitos de crianças menores de um ano ou menores de 5 anos, divididos pelo total de crianças do inquérito, segundo padronização da OMS ${ }^{18}$.

Para a verificação da diferença na prevalência e na mortalidade por diarréia nos períodos estudados utilizou-se o teste " $t$ " de Student. Na análise do diferencial de morbidade entre os indicadores foi utilizado o qui-quadrado de Mantel-Haenszel. Utilizou-se regressāo linear simples para avaliar a relação entre pluviosidade, temperatura ou umidade com a prevalência de doença diartéica. Os dados meteorológicos foram obtidos a partir do relatório meteorológico do Terminal da Ponta da Madeira, pertencente à Companhia Vale do Rio Doce, coletados na estaçāo da praia do Boqueirão, a uma latitude de $2^{\circ} 33^{\prime} 22^{\prime \prime}$, longitude de $44^{\circ} 21^{\prime} 32^{\prime \prime}$ e altitude de 9,40 metros.

O processamento e a análise estatística dos dados foram realizados em microcomputador, utilizando-se o programa Epi Info ${ }^{8}$.

\section{Resultados}

\section{Morbidade}

As maiores prevalências da doença diarréica foram observadas em maio de 1986 e novembro de 1987. As prevalências foram menores na estaçāo chuvosa (maio) e maiores na época seca (novembro) (Tabela 1). Análise de regressão linear simples mostrou associação estatisticamente significante entre prevalência de doença diarréica e precipitaçāo pluviométrica $(p<0,05)$.

Observou-se declínio estatisticamente significante na prevalência da diarréia entre os estudos censitários, realizados na época chuvosa, de maio86 e maio-89 $(p<0,05)$. Apesar das flutuaçôes observadas nos resultados, devido a fatores sazonais, observou-se tendência à diminuição da doença diarréica. Em 1986 foram detectados 6,3 episódios diarréicos por criança/ano, enquanto em 1989 esse número decresceu para 2,1 episódios/criança/ano.

Entre as razōes que podem explicar a reduçăo da morbidade pela doença diarréica, no período estudado, podem ser relacionados: aumento no percentual de domicílios servidos por água da rede pública, que passou de $56,6 \%$ para $91,1 \%$; redução do número de mães analfabetas e aumento daquelas com primeiro grau; aumento dos domicílios servidos por coleta de lixo, que passaram de $16,3 \%$, em 1986 , para $22 \%$, em 1989 ; aumento do percentual de famílias com renda entre 1 e 1,9 salários mínimos, diminuindo o percentual daquelas com menos de um salário e com 2 a 3 salários (Tabela 2).

Em termos de indicadores socioeconômicos e ambientais, considerando-se o ano de 1989, o bairto de Vila Palmeira é dotado de melhor infraestrutura urbana, $99,5 \%$ dos domicilios têm água da rede pública e 49,3\% das residências sảo servidas por rede de esgostos ou têm fossa séptica; é

Tabela 1 - Época, tipo de estudo, número de crianças entrevistadas, prevalência de diarréia, precipitaçāo pluviométrica, temperatura média e umidade relativa do ar em três áreas da Ilha de Săo Luís, 1986-1989.

\begin{tabular}{lccrccc} 
Época & Tipo & $\begin{array}{c}\text { Número de } \\
\text { crianças }\end{array}$ & $\begin{array}{c}\text { Prevalência } \\
(\%)\end{array}$ & $\begin{array}{r}\text { Pluviosidade* } \\
(\mathrm{em} \mathrm{mm})\end{array}$ & $\begin{array}{c}\text { Temperatura } \\
\text { média }\left({ }^{\circ} \mathrm{C}\right)^{*}\end{array}$ & $\begin{array}{c}\text { Umidade relativa } \\
\text { do ar }(\%)^{*}\end{array}$ \\
\hline Maio 86 & Censitário & 7.172 & 16,8 & 215,4 & 26,4 & 89,6 \\
Novembro 86 & Amostral & 590 & 16,1 & 1,8 & 28,2 & 84,0 \\
Novembro 87 & Amostral & 1.249 & 18,7 & 0 & 28,6 & 83,2 \\
Maio 88 & Amostral & 1,161 & 6,7 & 575,5 & 27,3 & 89,2 \\
Novembro 88 & Amostral & 1.221 & 13,9 & 3,4 & 29,6 & 86,0 \\
Maio 89 & Censitário & 6.695 & 7,8 & 441,5 & 26,3 & 85,5
\end{tabular}

* Fonte: Relatório metereológico do Terminal da Ponta da Madeira (Companhia Vale do Rio Doce). 
Tabela 2 - Evoluçảo dos indicadores socioeconómicos e ambientais em três áreas da Ilha de Sảo Luís, 1986-1989.

\begin{tabular}{|c|c|c|c|c|c|}
\hline \multirow[t]{2}{*}{ Indicador } & & \multicolumn{2}{|c|}{1986} & \multicolumn{2}{|c|}{1989} \\
\hline & & $n$ & $\%$ & $n$ & $\%$ \\
\hline \multirow[t]{2}{*}{$\begin{array}{l}\text { Renda Familiar } \\
\text { (em salários mínimos) }\end{array}$} & $\begin{array}{l}\text { menor de } 1 \\
1 \text { a } 1,9 \\
2 \text { a } 3 \\
3 \text { e mais }\end{array}$ & $\begin{array}{r}1.698 \\
2.726 \\
2.294 \\
384\end{array}$ & $\begin{array}{r}23,9 \\
38,4 \\
32,3 \\
5,4\end{array}$ & $\begin{array}{r}850 \\
4.002 \\
502 \\
446\end{array}$ & $\begin{array}{r}14,7 \\
69,0 \\
8,7 \\
7,7\end{array}$ \\
\hline & Total & 7.102 & 100,0 & 5.800 & 100,0 \\
\hline \multirow[t]{2}{*}{ Escolaridade da mãe } & $\begin{array}{l}\text { analfabeta } \\
\text { alfabetizada } \\
1^{2} \text { grau } \\
2^{2} \text { grau e mais }\end{array}$ & $\begin{array}{r}682 \\
1.053 \\
4.135 \\
1.177\end{array}$ & $\begin{array}{r}9,7 \\
14,9 \\
58,7 \\
16,7\end{array}$ & $\begin{array}{r}498 \\
229 \\
4.515 \\
1.388\end{array}$ & $\begin{array}{r}7,5 \\
3,5 \\
68,1 \\
20,9\end{array}$ \\
\hline & Total & 7.047 & 100,0 & 6.630 & 100,0 \\
\hline \multirow[t]{2}{*}{$\begin{array}{l}\text { Abastecimento de } \\
\text { água }\end{array}$} & $\begin{array}{l}\text { rede pública } \\
\text { poço coberto } \\
\text { poço descoberto } \\
\text { chafariz }\end{array}$ & $\begin{array}{r}3.986 \\
1.324 \\
1.252 \\
477\end{array}$ & $\begin{array}{r}56,6 \\
18,8 \\
17,8 \\
6,8\end{array}$ & $\begin{array}{r}6.002 \\
347 \\
212 \\
26\end{array}$ & $\begin{array}{r}91,1 \\
5,3 \\
3,2 \\
0,4\end{array}$ \\
\hline & Total & 7.039 & 100,0 & 6.587 & 100,0 \\
\hline \multirow[t]{2}{*}{ Destino do lixo } & $\begin{array}{l}\text { coletado } \\
\text { rua } \\
\text { maré } \\
\text { terreno baldio }\end{array}$ & $\begin{array}{r}1.170 \\
2.048 \\
802 \\
3.152\end{array}$ & $\begin{array}{l}16,3 \\
28,5 \\
11,2 \\
44,0\end{array}$ & $\begin{array}{r}1.468 \\
1.801 \\
706 \\
2.711\end{array}$ & $\begin{array}{l}22,0 \\
26,9 \\
10,6 \\
40,5\end{array}$ \\
\hline & Total & 7.172 & 100,0 & 6.686 & 100,0 \\
\hline
\end{tabular}

um bairro de ocupaçāo mais antiga, de população mais estável, sendo que $10,1 \%$ das familias recebem abaixo de um salário mínimo. $O$ bairro do Anjo da Guarda tem $85,1 \%$ dos domicílios com água encanada e destino dos dejetos adequado em $43,6 \%$ das residências. Em sua maioria é um bairro de ocupação mais recente, sem adequada estrutura urbano-viária e $11 \%$ das famílias recebem abaixo de um salário mínimo. Os dois bairros do Município de Ribamar têm a pior situação socioeconômica, pois $36,4 \%$ das famílias recebem menos que um salário mínimo. $O$ abastecimento d'água chega a $98,9 \%$ dos domićlios, porém apenas $13,8 \%$ desses têm destino adequado dos dejetos. As diferenças de renda familiar, abastecimento d'água encanada e destino adequado dos dejetos entre os bairros foram estatisticamente significantes.

A maior prevalência de diarréia ocorreu em Sāo José de Ribamar em relaçāo aos locais estudados; somente em maio de 89 o bairro da Vila Palmeira apresentou maior prevalência. Essas diferenças também foram estatisticamente significantes (Tabela 3 ).

Verificou-se maior prevalência de diarréia no grupo de 6 a 11 meses de idade, em ambos os estu-

Tabela 3 - Prevaléncia de diarréla aguda em menores de 5 anos em trés áreas da llha de São Luís, 1986-1989 (\%).

\begin{tabular}{|c|c|c|c|c|c|c|}
\hline \multirow[t]{2}{*}{ Bairro } & \multicolumn{2}{|r|}{1986} & \multirow{2}{*}{$\frac{1987}{\text { Novembro }}$} & \multicolumn{2}{|r|}{1988} & \multirow{2}{*}{$\begin{array}{l}1989 \\
\text { Maio }\end{array}$} \\
\hline & Maio & Novembro & & Maio & Novembro & \\
\hline $\begin{array}{l}\text { Vila Palmeira } \\
\text { Anjo da Guarda } \\
\text { São José de Ribamar }\end{array}$ & $\begin{array}{l}16,7 \\
16,7 \\
17,0\end{array}$ & $\begin{array}{l}16,2 \\
13,5 \\
25,3\end{array}$ & $\begin{array}{l}17,2 \\
19,0 \\
22,0\end{array}$ & $\begin{array}{r}5,3 \\
6,5 \\
12,7\end{array}$ & $\begin{array}{l}16,1 \\
10,9 \\
18,9\end{array}$ & $\begin{array}{l}8,1 \\
8,0 \\
6,6\end{array}$ \\
\hline Total & 16,8 & 16,1 & 18,7 & 6,7 & 13,9 & 7,8 \\
\hline
\end{tabular}


Tabela 4 - Prevalência de diarréia, segundo os indicadores anałisados nos estudos censitários em três areas da llha de São Luís, 1986-1989.

\begin{tabular}{|c|c|c|c|c|c|}
\hline \multirow[t]{2}{*}{ Indicador } & & \multicolumn{2}{|c|}{1986} & \multicolumn{2}{|c|}{1989} \\
\hline & & $\mathrm{n}$ & $\%$ & $n$ & $\%$ \\
\hline \multirow[t]{2}{*}{ Idade* } & $\begin{array}{l}0 \text { a } 5 \text { meses } \\
6 \text { a } 11 \text { meses } \\
1 \text { ano } \\
2 \text { anos } \\
3 \text { anos } \\
4 \text { anos }\end{array}$ & $\begin{array}{r}609 \\
774 \\
1.331 \\
1.465 \\
1.486 \\
1.497\end{array}$ & $\begin{array}{l}16,1 \\
26,2 \\
23,8 \\
17,1 \\
12,0 \\
11,3\end{array}$ & $\begin{array}{r}639 \\
871 \\
1.397 \\
1.332 \\
1.351 \\
994\end{array}$ & $\begin{array}{r}7,2 \\
13,1 \\
9,4 \\
8,4 \\
4,3 \\
5,8\end{array}$ \\
\hline & Total & 7.162 & & 6.584 & \\
\hline
\end{tabular}

\begin{tabular}{clrrrr}
$\begin{array}{c}\text { Escolari- até } \\
\text { dade alfabetizado }\end{array}$ & 1.735 & 16,9 & 727 & 5,9 \\
materna* & $1^{\circ}$ grau & 4.135 & 17,6 & 4.515 & 8,3 \\
& $2^{9}$ grau & 1.177 & 14,3 & 1.388 & 6,9 \\
\hline Total & 7.047 & & 6.630 &
\end{tabular}

- Indicadores com diferença estatisticamente significante pelo Qui-quadrado (em 86 e 89 - p<0,05)

Tabela 5 - Prevalência de diarréia segundo as variáveis do estudo censitários em três áreas da llha de São Luís em maio de 1989.

\begin{tabular}{|c|c|c|c|}
\hline Variável & & $\mathbf{n}$ & $\%$ \\
\hline \multirow[t]{2}{*}{$\begin{array}{l}\text { Renda Familiar } \\
\text { (em salários- } \\
\text { mínimos) }\end{array}$} & $\begin{array}{l}\text { menor de } 1 \\
\text { de } 1 \text { a } 1,9 \\
\text { de } 2 \text { a } 3 \\
\text { mais de } 3\end{array}$ & $\begin{array}{r}850 \\
4.002 \\
502 \\
446\end{array}$ & $\begin{array}{l}7,2 \\
7,5 \\
7,6 \\
9,9\end{array}$ \\
\hline & Total & 5.800 & \\
\hline \multirow[t]{2}{*}{$\begin{array}{l}\text { Abastecimento de } \\
\text { água" }\end{array}$} & $\begin{array}{l}\text { poço coberto } \\
\text { poço descoberto } \\
\text { rede geral }\end{array}$ & $\begin{array}{r}347 \\
212 \\
6.002\end{array}$ & $\begin{array}{r}9,8 \\
11,3 \\
7,5\end{array}$ \\
\hline & Total & 6.561 & \\
\hline \multirow[t]{2}{*}{$\begin{array}{l}\text { Destino dos } \\
\text { dejetos }\end{array}$} & $\begin{array}{l}\text { céu aberto } \\
\text { fossa negra } \\
\text { fossa séptica } \\
\text { maré } \\
\text { rede geral }\end{array}$ & $\begin{array}{r}676 \\
2.902 \\
2.229 \\
361 \\
399\end{array}$ & $\begin{array}{l}7,2 \\
9,1 \\
6,2 \\
9,1 \\
5,8\end{array}$ \\
\hline & Total & 6.567 & \\
\hline \multirow[t]{2}{*}{ Destino do lixo } & $\begin{array}{l}\text { coletado } \\
\text { maré } \\
\text { terreno baidio }\end{array}$ & $\begin{array}{r}1.468 \\
706 \\
2.711\end{array}$ & $\begin{array}{l}7,2 \\
7,9 \\
7,7\end{array}$ \\
\hline & Total & 4.885 & \\
\hline \multirow[t]{2}{*}{$\begin{array}{l}\text { Relaçāo dos pais } \\
\text { no emprego }\end{array}$} & $\begin{array}{l}\text { assalariado } \\
\text { autônomo } \\
\text { desempregado }\end{array}$ & $\begin{array}{r}3.639 \\
2.334 \\
654\end{array}$ & $\begin{array}{l}7,8 \\
7,4 \\
9,2\end{array}$ \\
\hline & Total & 6.627 & \\
\hline
\end{tabular}

dos censitários, seguido pelo grupo de um ano de idade. Em relação à escolaridade, a maior prevalência ocorreu nas famflias cujas mães tínham o primeiro grau (Tabela 4).

A prevalência da diarréia foi maior naquelas famílias com renda superior a três salários mínimos, e que se abasteciam de água de poço descoberto. Em relação ao destino do lixo e dos dejetos, as maiores prevalências foram encontradas naquelas que utilizavam a maré e fossa negra para os dejetos, e maré e terreno baldio para o lixo. A prevalência, segundo a relação dos pais no emprego, foi maior para os desempregados e assalariados (Tabela 5).

\section{Mortalidade}

$O$ coeficiente de mortalidade infantil em maio de 1986 foi de 44,0 por mil em crianças menores de um ano e de 12,8 por mil em menores de 5 anos. $O$ índice de mortalidade infantil proporcional por diartéia em menores de um ano foi de $55 \%$ e de $46 \%$ em menores de 5 anos.

O coeficiente de mortalidade infantil em maio de 1989 foi de 7,9 por mil em menores de um ano, e 4,9 por mil em menores de 5 anos. A diarreia foi responsável por $48 \%$ dos bbitos em menores de um ano e 44\% em menores de 5 anos. Comparando-se 1986 com 1989, a reduçāo da mortalidade infantil foi estaticamente significante ( $p<0,05$ ). Observou-se, ainda, redução na mortalidade proporcional por diarréia aguda em menores de 1 ano, que baixou de 55\%, em 1986 , para $48 \%$, em 1989 (Tabela 6).

Tabela 6 - Mortalidade infantil em três áreas da Ilha de Szao Luis, 1986-1989.

\begin{tabular}{|c|c|c|c|c|c|}
\hline Ano & Idade & Óbitos & $\begin{array}{l}\text { Obitos } \\
\text { por } \\
\text { diarréia }\end{array}$ & População & $\begin{array}{l}\text { Coeficiente } \\
\text { de mortali- } \\
\text { dade infantil }\end{array}$ \\
\hline 1086 & $\begin{array}{l}<1 \\
1-4 \\
<5\end{array}$ & $\begin{array}{l}64 \\
28 \\
92\end{array}$ & $\begin{array}{r}5 \\
7 \\
42\end{array}$ & & $\begin{array}{r}44,0 \text { por mil } \\
5,0 \text { por mil } \\
12,8 \text { por mil }\end{array}$ \\
\hline 1989 & $\begin{array}{l}<1 \\
1-4 \\
<5\end{array}$ & $\begin{array}{r}23 \\
9 \\
32\end{array}$ & $\begin{array}{r}11 \\
3 \\
14\end{array}$ & & $\begin{array}{l}7,9 \text { por mil } \\
2,4 \text { por mil } \\
4,9 \text { por mil }\end{array}$ \\
\hline
\end{tabular}

Observou-se a relação existente entre mortalidade infantil em menores de 5 anos e a renda familiar em salários mínimos. A mortalidade infantil foi maior naquelas famílias cujos pais ganhavam menos de um salário mínimo (Tabela 7). 
Tabela 7 . Mortalidade infantil em menores de 5 anos, segundo renda familiar em três áreas da llha de São Luís, 1986-1989.

\begin{tabular}{lrrr}
\hline $\begin{array}{l}\text { Renda familiar } \\
\text { (em salários- } \\
\text { mínimos) }\end{array}$ & Crianças & Obitos & Mortalidade \\
\hline menor de 1 & 1.698 & 31 & 18,3 por mil \\
1 a 1,9 & 2.726 & 41 & 15,0 por mi \\
2 a 3 & 2.294 & 19 & 8,3 por mil \\
3 e mais & 384 & 1 & 2,6 por mil \\
\hline Total & 7.172 & 92 & 12,8 por mil \\
\hline
\end{tabular}

\section{Discussāo}

A prevalência da diarréia aguda infantil em São Luís, em maio de 1986 (16,8\%), foi maior do que no Quênia ${ }^{21}$, em 1982 (2,2\%); também maior do que na Nigéria ${ }^{19}(8,1 \%)$; semelhante a Sergipe $(15,6 \%)$ e Rio Grande do Norte 23 , em 1991 $(15,4 \%)$, e menor do que na Bolívia ${ }^{17}(24,8 \%)$. Estudo desenvolvido pelo Unicef, em Sảo Luís, em 1991, mostrou prevalência de 15\%, semelhante à encontrada no presente estudo 8 .

Nos estudos de morbidade pode ocorrer uma dificuldade de entendimento sobre a definição de diarréia pela mãe, influenciando diretamente a taxa de prevalência e dificultando a comparação dos dados ${ }^{15}$. Episódios curtos e rápidos de diarréia normalmente sāo subestimados em inquéritos populacionais ${ }^{5}$.

A maior prevalência de diarréia em época nāo chuvosa foi também descrito por Huttly e col. ${ }^{12}$, em comunidades rurais da Nigéria. Com exceção de maio de 1986, as menores prevalências foram observadas na época chuvosa (maio).Não foi observada associaçăo estatisticamente significante entre temperatura ou umidade e prevalência de doença diarréica, provavelmente devido ao fato da pequena variabilidade destas no clima tropical amazônico.

As faixas etárias mais acometidas (6 a 11 meses e 1 ano) são as mesmas citadas em outros trabalhos $2,12,13$. As maiores taxas de doença diarréica são encontradas em crianças menores de um ano nåo alimentadas com leite materno. É conhecido o efeito protetor do leite materno ${ }^{10,17}$.

A morbidade por diarréía está relacionada com as condiçð̄es de vida da população, medida pelo destino inadequado dos dejetos e do lixo das moradias, a renda familiar e o índice de emprego ${ }^{25}$. No presente estudo, observou-se associaçāo estasticamente significante entre diarréia e escolaridade materna, abastecimento de água e destino dos dejetos, indicando que os programas de controle da doença diarréica devem enfatizar esses três itens. Houve variação na prevalência de diarréia nas três áreas analisadas, em funçāo das diferenças socioeconômicas e de saneamento ambiental entre estas.

A maior prevalência da diarréia nos dois estudos censitários foi observada nas famílias cujas mães tinham o primeiro grau de escolaridade. Na Bolívia, estudo mostrou resultados semelhantes, onde a maior prevalência da doença foi encontrada nas famílias com instruçăo escolar média, ou seja, com 4 a 9 anos de escolaridade ${ }^{17}$.

Esse mesmo estudo mostrou que a maior prevalência da diarréia foi observada nas familias em que os dejetos eram eliminados em fossas e 0 abastecimento de água feito por outras fontes que não a rede geral; resultados semelhantes aos do presente estudo, no período de maio de 1989. Na Bolívia, a maior incidência de diarréia em residências servidas de água potável, nos estratos socioeconômicos baixos, mostrou que a contaminaçāo persistiu, levantando a questão sobre a necessidade de que os investimentos públicos em saneamento se façam acompanhar de programas educativos ${ }^{17}$.

Estudo feito em Goiânia observou que a prevalência da diarréia é inversamente proporcional à disponibilidade de água potável e esgoto sanitário na comunidade 1 .

A redução da morbidade por diarréia observada no presente estudo, comparando-se os dois estudos censitários realizados na época chuvosa, maio de 1986 com maio de 1989, pode ser creditada à melhoria da escolaridade das māes e a maior cobertura do abastecimento d'água nas três áreas analisadas. Provavelmente podem estar envolvidas, ainda, melhorias nos programas educativos e nos serviços de saúde, nāo investigadas nessa oportunidade.

As causas de morte são semelhantes à situação encontrada nos países em desenvolvimento nos quais a diartéia representa uma das três principais causas de óbitos em menores de 5 anos. A Investigaçāo Interamericana de Mortalidade na Infância mostrou que a dirréia foi a causa principal em $28,6 \%$ dos casos estudados em menores de 5 anos ${ }^{14}$. No presente estudo o índice de mortalidade infantil proporcional por diarreia, em menores de 5 anos foi maior, sendo de 44\%, em 1989.

Em Bangladesh, a diarréia foi responsável por $40 \%$ das mortes em menores de um ano e $9 \%$ em menores de 5 anos $^{9}$; esses estudos mostram resultados bem inferiores se comparados com a presente pesquisa, de maio- 86 , em que a diarréia foi a 
causa de $55 \%$ dos óbitos em menores de um ano e $46 \%$ em menores de 5 anos.

A mortalidade infantil por diarréia pode ter sofrido esse decréscimo em decorrência de vários fatores, entre eles o incentivo ao uso da TRO. Em Goiânia, um estudo revelou que a TRO foi responsável pela queda de $65 \%$ no número de 6 bitos por diarréia, em menores de 5 anos ${ }^{1}$. Em Sāo Luís, possivelmente nesse período, pode ter havido uma expansāo da prática da TRO, influenciando na diminuiçăo da mortalidade infantil por essa causa.

Em estudos sobre mortalidade geralmente ocorre uma subestimativa dos óbitos provavelmente por fatores tais como dificuldade em estabelecer o tempo da ocorrência e omissão de informações. Entretanto, se a proporção dos óbitos não registrados for relativamente constantes, o estudo das tendências da mortalidade infantil pode ser feito ${ }^{3}$. No presente trabalho, apesar dos valores numéricos encontrados não poderem ser tomados como reais, a análise de tendências mostra decréscimo na mortalidade infantil em menores de um ano, que baixou de forma estatisticamente significante entre 1986 e 1989.

No período de maio de 1986 , da presente pesquisa, observou-se que a mortalidade infantil foi maior nos grupos de renda mais baixa, demostrando o quanto a renda familiar é um indicador importante para avaliar a qualidade de vida de uma população.

A desidratação é uma das maiores responsáveis pelo agravamento dos quadros diarréicos.

\section{Referênclas Bibliográficas}

1. BARBOSA, M.I. Mortalidade por diarréia aguda nos menores de cinco anos em Goiânia. J. Pediatr., 63:183-6, 1987.

2. BARROS, F.C. et al. Infant mortality in Southern Brazil: population based study of causes of death. Arcb. Dis. Cbild., 62: 487-90, 1987

3. BARROS, F.C. \& VICTORA, C.G. Epidemiologia da saúde infantil: um manual para diagnósticos comunitarios. Såo Paulo, Hucitec/Unicef, 1991

4. BENfCIO, M.H.D'A et al. Estudo das condiçỏes de saúde das crianças do Município de São Paulo, SP(Brasil) 1984-1985. IV - Doenças diarréicas. Rev. Saúde Püblica, 21:23-8, 1987.

5. BERN, C. et al. Magnitud del problema global de las enfermedades diarréicas: actualización decenal. Bol. Of. Sanit. Panam., 115:523-35, 1993.

6. CORTEGUERA, R.R. Mortalidade por enfermidades diaréicas agudas em menores de 5 anos. Cuba, 1959-1983. Rev. Cuabana Hig. Epidemiol., 24:131-45, 1986.
Em São Luís, trabalho desenvolvido pela Unicef ${ }^{7}$, mostrou que a desitrataçāo foi responsável por $21,4 \%$ dos óbitos em menores de um ano. As doenças responsáveis pelo maior número de óbitos em menores de um ano, teriam condiçōes de ser evitadas, caso houvesse preocupação maior com a sua prevenção, especialmente em áreas carentes de saneamento ambiental. No entanto, o que se observa é que os grupos mais expostos à diarréia em geral são os que menos recebem atenção dos serviços de saúde. Cerca de metade dos b́bitos por diarréja ocorre antes de a criança ter oportunidade de contato com os serviços ${ }^{20}$.

A mortalidade infantil é um dos indicadores que melhor retrata o nível de vida, de saúde e as condiçōes socioeconômicas de uma populaçāo. Tendo em vista que năo houve grandes melhorias na renda familiar no período estudado, a reduçāo da mortalidade infantil por diarréia, nos 3 locais da ilha de São Luíz, tende a confirmar a melhoria dos indicadores sanitários em época de crise econômica, em decorrência do aumento da escolaridade e da expansão da rede de abastecimento de água $e$, possivelmente, da ação dos serviços de saúde, seja no melhor acompanhamento preventivo de crianças menores de 5 anos, seja no incremento dos níveis de cobertura vacinal. As conclusões do presente trabalho podem ser úteis para outros centros urbanos brasileiros com características socioeconômicos e ambientais semelhante.

7. DEAN, A.G. et al. Epi Info Version 5.01b; a word processing database and statistics program for epidemiology on microcomputers. Atlanta, Centers for Disease Control, 1990.

8. CRIANÇAS e adolescentes no Maranhão: saúde, educaçào e trabatho. São Luís, Governo do Estado do Maranhão/UNICEF, 1992.

9. FAUVEAL, V. et. al. Diarrhoea mortality in rural Bangladesh children. J. Trop. Pediatr., 37:316, 1991.

10. FEACHEM, R.G. \& KOBLINSKY, M.A. Medidas para el control de las enfermidades diarreicas em niños menores de cinco años. 4. Fomento de la lactancia materna. Bol. Of. Sanit. Panam., 99: 464-97, 1985.

11. GRIFFIN, P.M. et al. Risk factors for fatal diarrhoea: a case-control study of African children. Am. J. Epidemiol., 128:1322-9, 1988.

12. HLTTLY, S.R.A. et al. The epidemiology of acute diarrhoea in a rural community in Imo State, Nigeria. Trans. R.Soc. Trop. Med. Hyg., 81: 865-70, 1987

13. JINADU, M.K. et al. Childhood diarrhoea in nural Nigeria: studies on prevalence, mortality and 
socioenvironmental factors. I. Diarrboeal Dis. Res., 9:322-7, 1991.

14. IAURENTI, R. Resultados e açòes apontadas pela investigação interamericana de mortalidade na infância no Brasil. Bol. Of. Sanit. Panam., 82:344-60, 1977.

15. LEEWENBURG, $J$. et al. The incidence of diarrhoeal disease in the under-five population. Trop. Geogr. Med., 30:383-91, 1978.

16. MARCONDES, E A situaçào e prospectivas da mortalidade em menores de cinco anos na América Latina: a situação no Brasil. Pediatria, 10:157-65, 1989.

17. MURILIO, A. de la \& COLOMA, R.B. Enfermidad diarreicas en areas urbanas da Bolivia: morbimortalidad en niños de 0 a 5 años. Salud Boliviana, 2:274-90, 1984.

18. ORGANIZACIOON PANAMERICANA DE LA SALUD, Metodologia para preparar una encuesta para medir el problema de las enfermidades diarreicas en un pais. Washington. 1984. (Programa de Salud Maternoinfantil).

19. OYEJIDE, C.O. \& FAEBAMI, A.H. An epidemiology study of rotavirus diarrohea in a cohort of nigerian infantis: II. Incidence of diarshoea in the first two years of life. Int. J. Epidemiol., $7: 908-12,1988$
20. RILEY, L,W, et al, Factores de riesgo de diarrea infantil aguda en una comunidad rural de Chiapas, México: una estrategia de intervención. Bol. Of. Sanit. Panam., 108:93-9, 1990.

21. SNYDER, J. D. \& MERSON, M.H. The magnitude of the global problem of acute diarroheal disease: a review of active surveillance date. Bull World Healtb Organ., 60:605-13, 1982.

22. VASCONCELOS, S.F. de. Mortalidade por diarrêia nos menores de cínco anos na cidade de Recife, Brasil, no periodo de 1980-1984. J. Bras. Med., 50:24-9, 1986.

23. VICTORA, C.G. et al. A saúde das crianças dos Estados do Ceará, Rio Grande do Norte e Sergipe, Brasil: descriçào de una metodologia para diagnósticos comunitários, Rev. Saúde Publica, 25:218-25, 1991

24. VICTORA, C.G. et al. Infant feeding on deaths du to diarthoea. Am. J. Epidemiol., 129: 1032-41, 1989.

25. VICTORA, C.G, et al. Water supply, sanitation and housing in ralation to the risk of infant mortality from diarrhoea. Int./. Epidemiol., 17:651-4, 1988.

26. YACH, D. et al. The impact of diarroheal disease on childhood deaths in the RSA, 1968-1985. S Afr. Med. J., 76:472-5, 1989.

\begin{abstract}
Six cross-sectional studies involving children under five years of age in three places on S. Luiz island, i.e., Vila Palmeira, Anjo da Guarda and S. Jose de Ribamar, were performed. A standardized questionnaire on the presence of diarrhoea in the previous 2 weeks was answered by the mothers or by those responsible for the children. Two population based studies (in May 1986 and May 1989) and four sample based surveys (in November of 1986, 1987 and 1988 and in May 1989) were carried out. The prevalence of diarrhoes was highest in May, 1986 and November, 1987. The highest prevalence occurred in S. Jose de Ribamar. The distribution of cases according to age showed a higher prevalence among children of 6-11 months and between 1 and 2 years of age. The prevalence of diarthoea was highest among the families: that excreted directly into the sea or a iatreen; that used water from uncovered wells; that threw their garbage into the sea; and whose bread-winners were unemployed. Diarrhoea was the principal cause of death in both surveys. Infant mortality, in May 1986, was 44.0 per thousand in children under 1 year of age and 12.8 in children under 5 years oid; in May 1989 it was 7.9 per thousand and 4.9 per thousand respectively. The decrease in child morbidity and mortality due to diarhoea between 1986 and 1989 was statistically significant.
\end{abstract}

Diarrhoea, epidemiology. Infant mortality. 